\title{
Epidemiology of Gastrointestinal Disease among Children and Adolescents in Kazakhstan: 2012-2019
}

\author{
Alikhan Zhaksylyk $^{1}$ (D) Ardak Nurbakyt $^{2 *}$ (D) Andrej Grjibovski $^{3}$ D, Galina Kaussova ${ }^{4}$ (D) Myrzataj Buleshov $^{5}$ (D) \\ ${ }^{1}$ Department of Scientific and Clinical Work, Doctoral and Master's Programs, Doctoral Student, South Kazakhstan Medical \\ Academy, Kazakhstan's Medical University, Almaty, Kazakhstan; ${ }^{2}$ Department of Epidemiology, Evidence-Based Medicine and \\ Biostatistics, Kazakhstan's Medical University, Almaty, Kazakhstan; ${ }^{3}$ Central Research Laboratory, Northern State Medical \\ University, Ministry of Health of the Russian Federation, Arkhangelsk, Russia; ${ }^{4}$ Department of Public Health and Social \\ Sciences, Kazakhstan's Medical University, Almaty, Kazakhstan; ${ }^{5}$ Department of Preventive Medicine and Dental Disciplines, \\ Khoja Akhmet Yassawi International Kazakh-Turkish University, Turkistan, Kazakhstan
}

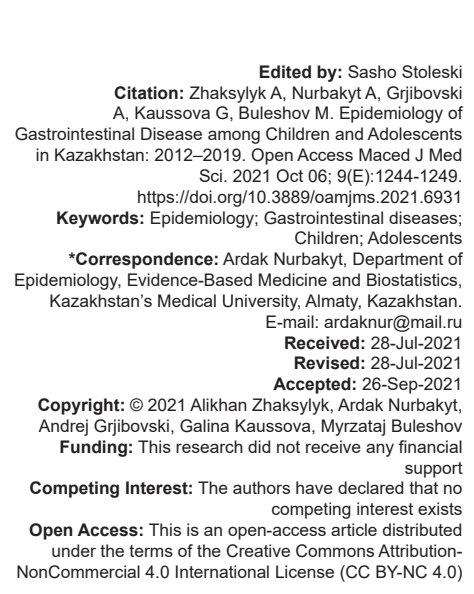

\section{Introduction}

Pediatric gastrointestinal disease constitutes a group of heterogenic disorders with different etiology and pathophysiologic pathways. These should be distinguished from functional gastrointestinal disorders, such as irritable bowel syndrome and functional constipation, when a comprehensive medical evaluation fails to detect the underlying organic disease. Although less prevalent, gastrointestinal disease in children is potentially associated with severe consequences and failure to thrive and thus, deserves to be considered in details [1].

Childhood gastritis and duodenitis present an inflammation of gastric or duodenal mucosa and are commonly manifested by abdominal pain, nausea and vomiting. Among the predisposing factors of gastritis are increase in secretion of gastric acid and infestation with Helicobacter pylori [2]. As for the childhood duodenitis, it is often caused by celiac disease and inflammatory bowel disease - one of the most frequent immune-mediated diseases. If childhood gastritis is rather commonly diagnosed, duodenitis appears to be a more rare diagnostic entity [3].

Stomach and duodenal ulcers are potentially more dangerous than gastritis and duodenitis and might be exacerbated by them. Like in case with gastritis/duodenitis, pediatric stomach and duodenal ulcers are provoked by increased secretion of gastric acid and $H$. pylori infection. Other risk factors include exposure to smoking, caffeine, and intake of nonsteroidal anti-inflammatory drugs. Epigastric burning and pain are the symptoms of stomach and duodenal ulcers in children, which may also be asymptomatic. Ulcers are associated with increased risk of bleeding, pyloric obstruction, perforation, and even gastric cancer later in life [4]. 
Unlike adults, children are exposed to gallbladder disease to a lesser extent, but this trend is gradually changing. Perhaps, gallstones are the most typical type of gallbladder disease and these manifests by acute or chronic abdominal pain, nausea, and vomiting. Fat-rich diet, overweight and obesity, genetic predisposition, Crohn's disease, and cerebral palsy are the provocative factors. Biliary dyskinesia and acalculous cholecystitis are among the pediatric gallbladder disease that is not accompanied by the stone formation [5].

Acute and chronic pancreatitis constitutes the bulk of pancreatic disease in children. It has to be noted that pancreatitis is rather uncommon in pediatric setting and its prevalence increases at adolescence. The disease is associated with elevated morbidity and mortality and acute abdominal pain in epigastric area is one of the most frequent symptoms. Apart from acute and chronic forms, pancreatitis could be hemorrhagic, necrotic, and inherited. The natural history of pediatric pancreatitis is not well-understood and thus, there is a lack of evidence-based approach in its diagnosis and treatment. In addition to pancreatitis, pancreatic insufficiency and congenital anomalies are two other common forms of pediatric pancreatic disorders [6].

Inflammatory bowel disease is more usual in adolescents and young adults, but is becoming increasingly customary in children. In fact, the disease is composed of a set of inflammatory disorders, to which also belong ulcerative colitis and Crohn's disease. Inflammatory bowel disease in its classic manifestation presents by abdominal pain, bloody diarrhea and weight loss, but quite often it may be exhibited by such extra-intestinal manifestations as anemia or failure to thrive [7]. Like in case with any pediatric gastrointestinal disease, special attention should be paid to child growth and development and good psychosocial functioning.

Overall, there is insufficient evidence on epidemiology of pediatric gastrointestinal disease in different countries, while these data are needed for planning of healthcare services. Kazakhstan is Central Asia country with huge differences in climate and eating habits between provinces. This study is aiming at epidemiological analysis of both national and local incidence rates of pediatric gastrointestinal disorders in the Kazakhstani population over the period from 2012 to 2019.

\section{Materials and Methods}

\section{Study design and procedures}

This study had a retrospective cross-sectional design and was conducted in two steps. On the first step, we applied for the nation-wide database that is kept by the Republican Center for Health Development (RCHD) - the major data source on the country's health statistics. The RCHD through its branches located in each province collects data on the reported health conditions, which are then translated into medical codes of the International Classification of Diseases, Revision 10 (ICD 10). From this database, we extracted records on all patients presented at the country's health-care facilities with K00-K95 ICD-10 codes. Our further action was to select data on all children (defined as individuals aged 0-14 years) and adolescents (defined as individuals aged 15-17 years) during the period 2012 to 2019 . Besides, we specifically looked at data of pediatric patients with the following ICD-10 codes: K25 (gastric ulcer), K26 (duodenal ulcer), K80 (cholelithiasis), K81 (cholecystitis), and K83.0 (cholangitis).

On the second step, we applied for the database kept by the branch of RCHD in Turkestan province (earlier known as South-Kazakhstan Province). The study in specific province was first attempt to evaluate a situation in Kazakhstan. From this, we extracted records on all children and adolescents presented at local health-care facilities with the following ICD-10 codes: K25 (gastric ulcer), K26 (duodenal ulcer), K29 (gastritis and duodenitis), K50-K52 (non-infective enteritis and colitis), and K80-K87 (disorders of gallbladder, biliary tract, and pancreas). Like in case with the national statistics, we selected the data on all children (individuals aged 0-14 years) and adolescents (individuals aged 15-17 years) during the period 2012-2018.

The study required no approval from the local ethics committee because it relied solely on the anonymized data.

\section{Statistical analysis}

All statistical analyses were performed with the help of IBM SPSS Statistics 20 software. We used the obtained data to calculate national incidence rates with the help of the following formula:

Incidence $=$ number of individuals who were diagnosed with the disease by the end of the year/midyear population *100,000.

The following formula was used to calculate the incidence rates for the population of Turkestan province:

Incidence $=$ number of individuals who were diagnosed with the disease by the end of the year/mid-year population * 1000 .

Data on the mid-year number of children/adolescents were obtained from the Demographic Yearbooks, issued by the Agency of Statistics of the Republic of Kazakhstan from 2012 to 2019 . 


\section{Results}

There was little variation in national incidence rates of gastrointestinal disease in both children and adolescents during 2012-2019. From 2012 to 2015, these rates tended to be higher in adolescents, while in the beginning of 2016 the trend has changed and incidence rates of gastrointestinal disease in children begun to prevail. In children, the incidence varied from 5906.6 per 100,000 population in 2014 to 7760.4 per 100,000 population in 2017. As for adolescents, the incidence rate ranged between 6566.2 and 9468.6 per 100,000 population, which were observed in 2019 and 2014, respectively (Figure 1).

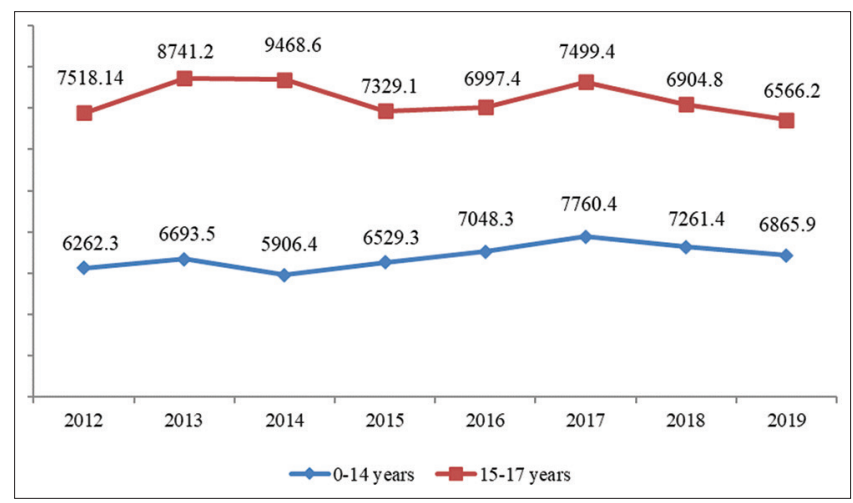

Figure 1: National incidence of gastrointestinal disease in children (0-14 years) and adolescents (15-17 years), 2012-2019 (per 100,000 population)

Unlike overall incidence rates of gastrointestinal disease, the incidence of gastric and duodenal ulcer in adolescents significantly exceeded that in children during the whole study period. The highest incidence of gastric and duodenal ulcers in adolescent population was reported for 2012 and 2013, when it constituted 186.5 and 189.2 per 100,000 population, respectively. Beginning 2014, it experienced a rapid decline reaching the level of 69.5 per 100,000 population in 2018. Likewise, the incidence of gastric and duodenal ulcers in pediatric population was the highest within the period from 2012 to 2014, after which it subjected to a gradual decline with the lowest level seen in 2019 (6.6 per 100,000) - Figure 2.

According to Figure 3, during the study period the incidence of pediatric gallbladder disease (cholelithiasis, cholecystitis, and cholangitis) remained rather stable and was substantially lower than that in adolescents with the maximal level observed in 2012 (196 per 100,00 population) and the minimal level seen in 2019 (141 per 100,000 population). The incidence of gallbladder disease in adolescents was also characterized by a relative stability ranging between 548.9 per 100,000 population in 2013 and 418.9 per 100,000 per population in 2019.

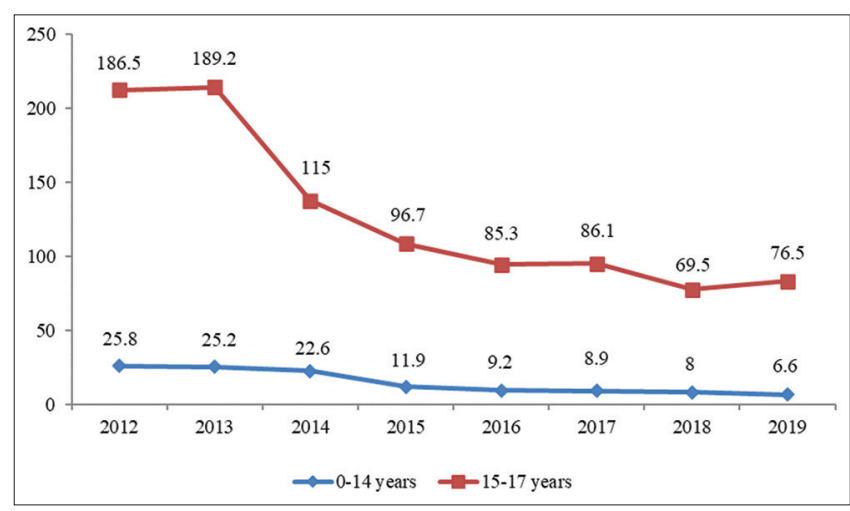

Figure 2: National incidence of gastric and duodenal ulcers in children (0-14 years) and adolescents (15-17 years), 2012-2019 (per 100,000 population)

Table 1 presents the incidence rates of selected gastrointestinal diseases in children of Turkestan province for the period of 2012-2018. In comparison to 2012, the incidence of gastritis/duodenitis and gastric/duodenal ulcer was gradually declining, while the incidence rates of other gastrointestinal diseases were less stable. After a transient decline, which was observed in 2014 and 2015, the incidence of gallbladder disease continued to grow, while the incidence of pancreatic disorders experienced a short-term elevation in 2015 and continued to decline afterwards, dropping to 0.77 per 1000 in 2018 .

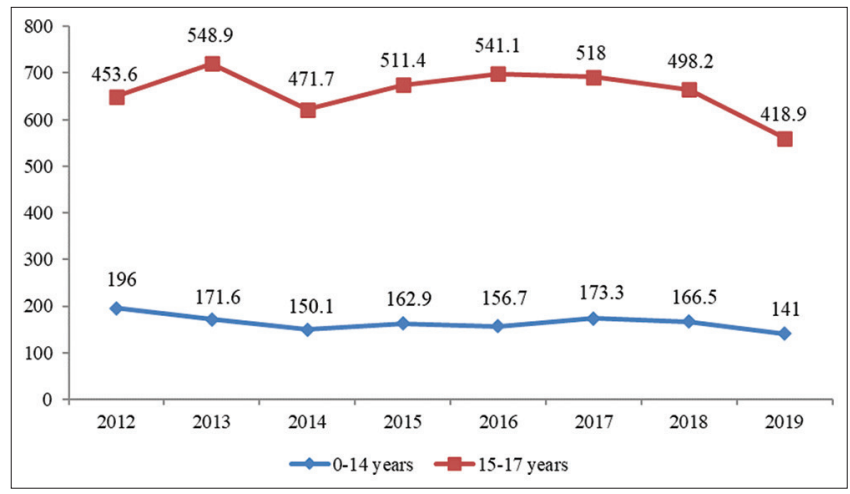

Figure 3: National incidence of gallbladder disease in children (0-14 years) and adolescents (15-17 years), 2012-2019 (per 100,000 population)

In parallel with the national rates, adolescents of Turkestan province had higher incidence of gastrointestinal disease as compared to children. The incidence of gastritis/duodenitis experienced a drop in 2015, reaching the level of 5.5 per 1000 population, but it began to grow already in the next year. This was also true for gastric/duodenal ulcers, the incidence of which substantially declined in 2013 but was stably growing since 2014. In comparison with 2012, the incidence of gallbladder disease was increasing and the maximal rate was observed in 2016 (63.7 per 1000 population) - Table 2. 
Table 1: Incidence of gastrointestinal disease in children (0-14 years) of Turkestan province, 2012-2018 (per 1000 population)

\begin{tabular}{|c|c|c|c|c|c|c|c|}
\hline Type of disease & 2012 & 2013 & 2014 & 2015 & 2016 & 2017 & 2018 \\
\hline \multicolumn{8}{|l|}{ All types of gastrointestinal disease } \\
\hline Incidence rate & 184.94 & 191.59 & 176.52 & 168.97 & 180.53 & 181.51 & 169.53 \\
\hline \% in comparison to 2012 & 100 & 103.59 & 95.45 & 91.36 & 97.61 & 98.14 & 91.67 \\
\hline$\%$ in comparison to the previous year & & +3.59 & -8.14 & -4.09 & +6.25 & +0.53 & -6.47 \\
\hline \multicolumn{8}{|l|}{ Gastritis and duodenitis } \\
\hline Incidence rate & 27.04 & 24.58 & 23.14 & 22.46 & 22.38 & 25.63 & 20.51 \\
\hline$\%$ in comparison to 2012 & 100 & 90.70 & 85.57 & 83.06 & 82.76 & 94.78 & 75.85 \\
\hline$\%$ in comparison to the previous year & & -9.30 & -5.13 & -2.51 & -0.30 & +12.02 & -18.93 \\
\hline \multicolumn{8}{|l|}{ Gastric and duodenal ulcer } \\
\hline Incidence rate & 0.76 & 0.61 & 0.66 & 0.58 & 0.56 & 0.57 & 0.64 \\
\hline$\%$ in comparison to 2012 & 100 & 80.26 & 86.84 & 76.31 & 73.68 & 75.0 & 84.21 \\
\hline$\%$ in comparison to the previous year & & -19.74 & +6.58 & -10.53 & -2.63 & +1.32 & +9.21 \\
\hline \multicolumn{8}{|l|}{ Disorders of gallbladder and biliary tract } \\
\hline Incidence rate & 39.51 & 40.07 & 39.02 & 38.67 & 41.23 & 44.48 & 43.65 \\
\hline$\%$ in comparison to 2012 & 100 & 101.30 & 98.72 & 97.80 & 104.30 & 112.34 & 107.63 \\
\hline$\%$ in comparison to the previous year & & +1.30 & -2.58 & -0.92 & +6.50 & +8.04 & -2.71 \\
\hline \multicolumn{8}{|l|}{ Disorders of pancreas } \\
\hline Incidence rate & 1.25 & 0.65 & 0.80 & 1.73 & 1.02 & 0.79 & 0.77 \\
\hline \% in comparison to 2012 & 100 & 52.00 & 64.00 & 138.42 & 81.64 & 63.22 & 61.47 \\
\hline$\%$ in comparison to the previous year & & -48.00 & +12.00 & +74.42 & -56.78 & -18.42 & -1.75 \\
\hline \multicolumn{8}{|l|}{ Non-infective enteritis and colitis } \\
\hline Incidence rate & 3.53 & 3.71 & 3.85 & 3.01 & 3.06 & 3.19 & 4.40 \\
\hline$\%$ in comparison to 2012 & 100 & 105.03 & 109.06 & 85.26 & 86.68 & 90.36 & 124.64 \\
\hline$\%$ in comparison to the previous year & & +5.03 & +4.03 & -23.80 & +1.42 & +3.68 & +34.28 \\
\hline
\end{tabular}

\section{Discussion}

This epidemiological study was planned to perform analysis of national and provincial incidence rates of pediatric gastrointestinal disease in Kazakhstan over the period of 8 years (2012-2019). In general, the national incidence of pediatric disease was characterized by relative stability, while the incidence of both peptic ulcers and gallbladder disease in adolescents substantially exceeded that in children. As for the provincial rates, the incidence of gastritis/duodenitis and peptic ulcers was gradually declining, while that of gallbladder disease was subjected to growth over the past years. Adolescents had higher rates of gastrointestinal disease both at national and provincial levels.

In contrast with adult gastrointestinal disease, there is a dearth of international data on epidemiology of pediatric gastrointestinal disease and this is particularly true for certain areas of the world, like newly independent Central Asian countries, to which belongs
Kazakhstan. These data are needed for planning and provision of health-care services and might enable forecasting of the future trends. This implies both allocation of additional resources and shifting the focus toward more important health issues. For instance, if the trends are likely to grow, more credit hours should be envisaged in current curriculums [8].

The rates of gastric/duodenal ulcers in children are lower than those in adults and range between $2 \%$ and $8 \%$, while the incidence of bleeding ulcers is even lower and constitutes around 0.5-4.4 per 100,000 population [9]. To certain extent, our data support these findings: The incidence of peptic ulcer was higher in adolescents, probably representing the transition to adulthood. Gastritis and duodenitis are closely inter-related with peptic ulcers, sharing similar etiology and pathophysiology. $H$. pylori infestation is the major causative agent and thus, understanding epidemiology of this infection gives insights into the spread of gastritis and gastric ulcers.

In most cases, $H$. pylori infection is acquired in early childhood and manifests as chronic gastritis.

Table 2: Incidence of gastrointestinal disease in adolescents (15-17 years) of Turkestan province, 2012-2018 (per 1000 population)

\begin{tabular}{|c|c|c|c|c|c|c|c|}
\hline Type of disease & 2012 & 2013 & 2014 & 2015 & 2016 & 2017 & 2018 \\
\hline \multicolumn{8}{|l|}{ All types of gastrointestinal disease } \\
\hline Incidence rate & 175.0 & 221.1 & 212.9 & 203.6 & 217.9 & 174.9 & 209.9 \\
\hline \% in comparison to 2012 & 100 & 126.3 & 121.7 & 116.3 & 124.5 & 99.9 & 119.9 \\
\hline$\%$ in comparison to the previous year & & +26.3 & -3.7 & -4.4 & +7.0 & -19.7 & +20.0 \\
\hline \multicolumn{8}{|l|}{ Gastritis and duodenitis } \\
\hline Incidence rate & 56.1 & 62.3 & 51.5 & 65.8 & 69.3 & 71.8 & 69.4 \\
\hline$\%$ in comparison to 2012 & 100 & 111.1 & 91.8 & 117.3 & 123.5 & 128.0 & 123.7 \\
\hline$\%$ in comparison to the previous year & & +11.1 & -17.4 & +27.8 & +5.3 & +3.6 & -3.3 \\
\hline \multicolumn{8}{|l|}{ Gastric and duodenal ulcer } \\
\hline Incidence rate & 6.50 & 3.70 & 3.81 & 4.40 & 4.30 & 4.59 & 4.70 \\
\hline \% in comparison to 2012 & 100 & 56.9 & 58.6 & 67.7 & 66.2 & 70.6 & 82.3 \\
\hline$\%$ in comparison to the previous year & & -43.1 & +2.9 & +16.5 & -2.3 & +6.7 & +2.4 \\
\hline \multicolumn{8}{|l|}{ Disorders of gallbladder and biliary tract } \\
\hline Incidence rate & 41.7 & 51.5 & 59.8 & 58.9 & 63.7 & 61.3 & 59.6 \\
\hline \% in comparison to 2012 & 100 & 123.0 & 142.9 & 140.7 & 152.2 & 146.5 & 142.5 \\
\hline$\%$ in comparison to the previous year & & +23.0 & +16.1 & -1.5 & +8.2 & -3.7 & -1.6 \\
\hline \multicolumn{8}{|l|}{ Disorders of pancreas } \\
\hline Incidence rate & 2.01 & 1.30 & 1.52 & 1.58 & 0.63 & 2.68 & 1.94 \\
\hline \% in comparison to 2012 & 100 & 64.7 & 75.6 & 78.4 & 31.4 & 133.3 & 96.5 \\
\hline$\%$ in comparison to the previous year & & -35.3 & +16.9 & +3.9 & -60.1 & +325.4 & -28.4 \\
\hline \multicolumn{8}{|l|}{ Noninfective enteritis and colitis } \\
\hline Incidence rate & 0.80 & 1.01 & 0.81 & 1.19 & 2.14 & 3.28 & 2.90 \\
\hline$\%$ in comparison to 2012 & 100 & 126.3 & 101.2 & 148.8 & 267.5 & 410.0 & 362.5 \\
\hline$\%$ in comparison to the previous year & & +26.3 & -19.9 & +46.9 & +79.8 & +53.3 & -11.6 \\
\hline
\end{tabular}


In later life it may transform into peptic ulcer or even gastric cancer. The prevalence of $H$. pylori infection is higher in poorer nations and it is becoming rather uncommon in the developed world. $H$. pylori infection is a Gram-negative bacillus with oral-to-oral or fecal-to-oral route of transmission. For this reason, such indicators of socioeconomic status as household density, cooking habits, and family-bound hygiene in general, influence the risk of acquiring $H$. pylori infection during childhood. Because the prevalence of $H$. pylori infestation increases with age, as many as $25 \%$ of individuals acquire the infection by the age of 18 years [10].

During recent years, the etiology of pediatric gallbladder disease has been changing and this was attributed to the increasing rates of overweightand obesity. If cholelithiasis was rare in older cohorts, ranging within $0.1-1.0 \%$ of unselected pediatric population, nowadays it affects up to $2 \%$ of children and obesity is responsible for $8-33 \%$ of all gallstones observed in children [11]. Other risk factors include teenage pregnancy and the use of oral contraceptives. Interestingly, the growing prevalence of pediatric gallbladder disease may be also explained by a greater access to such imaging studies as abdominal ultrasonography, because as many as $40-51 \%$ of children with cholelithiasis are asymptomatic [5]. So far, we were unable to detect the rise in rates of pediatric gallbladder disease, which is probably explained by a relatively short duration of our study that lasted only for 8 years.

Both acute and chronic pancreatitis are becoming increasingly common in children and the incidence rates are between 3.6 and 13.2 per 100,000 population [6]. Etiology of acute pancreatitis in children is different from that in adults and includes intake of certain medications, exposure to trauma or infectious disease, and presence of such anatomic abnormalities as choledochal cysts [12]. Unfortunately, there is a lack of robust data on how pediatric pancreatitis is best managed and most clinical guidelines rely on the evidence collected from the controlled trials on adult patients. Thus, this drawback is yet to be overcome and clinicians dealing with pediatric pancreatitis will gain more confidence in their ability to combat this troublesome condition.

Several local issues need to be considered when discussing the spread of gastrointestinal disease in pediatric population. The inverse relationship was established between Vitamin $D$ status and the rates of inflammatory bowel disease [13], gastritis, peptic ulcer [14], and pancreatitis [15]. Kazakhstan is a Vitamin D deficient area [16] and this may contribute to the rates of gastrointestinal disease. Besides, it was demonstrated that Kazakhstani parents having a child with chronic disorder are more likely to abandon him/her as compared with the parents of healthy children [17]. Therefore, social dimension of child health also needs to be taken into consideration.

Although our study has a number of benefits such an evaluation of the epidemiological features and understanding of general picture in important public health problem, it is not flawless and the main limitation originates from its retrospective design. For instance, we were unable to provide the in-depth analysis on various types of gastrointestinal disease and coexisting and/or predisposing conditions, with disaggregation by child's age, sex, and time of onset. However, the main benefit of our study is that it includes all cases of pediatric gastrointestinal disease registered within a reasonable time period, equal to 8 years. To support the national statistics, we obtained more detailed information from Turkestan Province, which is by far the most populated province in the country. Obviously, there is a need for more detailed research, preferably with the prospective design, focusing on such important issues as the rates of $H$. pylori infection in the Kazakhstani child and adolescent population.

\section{Conclusion}

The present study investigates epidemiology of pediatric gastrointestinal disease in Kazakhstan on the basis of national and provincial statistics obtained from the Republican Centre for Health Development. At present, there is a lack of such data, which are needed for planning and implementation of targeted public health interventions. The analysis of incidence rates with a focus on such burdensome condition as peptic ulcer will shed light on the resources needed to keep this problem under control. Obviously, the analysis of national and local incidence rates of gastrointestinal disorders among children and adolescents in Kazakhstan showed that more studies are needed to obtain in-depth understanding of risk factors associated with gastrointestinal disease in child and adolescent population of Kazakhstan, including the prevalence rates of $H$. pylori infection. Besides, a national registry on pediatric gastrointestinal disease should be envisaged to overcome the lack of essential data.

\section{Contributors}

All authors have contributed to manuscript writing and review, and have approved the final version.

\section{Acknowledgments}

We thank all the patients who participated in the study. 


\section{References}

1. Ashorn M. Gastrointestinal diseases in the paediatric age groups in Europe: Epidemiology and impact on healthcare. Aliment Pharmacol Ther 2003;18(Suppl 3):80-3. http://doi. org/10.1046/j.0953-0673.2003.01730.x

PMid: 14531747

2. Islek A, Yilmaz A, Elpek GO, Erin N. Childhood chronic gastritis and duodenitis: Role of altered sensory neuromediators. World J Gastroenterol 2016;22(37):8349-60. http://doi.org/10.3748/ wjg.v22.i37.8349

PMid:27729741

3. Alper A, Hardee S, Rojas-Velasquez D, Escalera S, Morotti RA, Pashankar DS. Prevalence and clinical, endoscopic, and pathological features of duodenitis in children. J Pediatr Gastroenterol Nutr. 2016;62(2):314-6. http://doi.org/10.1097/ MPG.0000000000000942

\section{PMid:26252915}

4. Lee EJ, Lee YJ, Park JH. Usefulness of ultrasonography in the diagnosis of peptic ulcer disease in children. Pediatr Gastroenterol Hepatol Nutr. 2019;22(1):57-62. http://doi. org/10.5223/pghn.2019.22.1.57 PMid:30671374

5. Walker SK, Maki AC, Cannon RM, Foley DS, Wilson KM, Galganski LA, et al. Etiology and incidence of pediatric gallbladder disease. Surg (United States). 2013;154(4):927-33. http://doi.org/10.1016/j.surg.2013.04.040

PMid:24074432

6. Morinville VD, Husain SZ, Bai H, Barth B, Alhosh R, Durie PR, et al. Definitions of pediatric pancreatitis and survey of present clinical practices. J Pediatr Gastroenterol Nutr. 2012;55(3):261-5. http://doi.org/10.1097/MPG.0b013e31824f1516

PMid:22357117

7. Rosen MJ, Dhawan A, Saeed SA. Inflammatory bowel disease in children and adolescents. JAMA Pediatr. 2015;169:1053-60. http://doi.org/10.1001/jamapediatrics.2015.1982 PMid:26414706

8. Dauletyarova M, Semenova Y, Kaylubaeva G, Manabaeva G, Khismetova Z, Akilzhanova Z, et al. Are women of East Kazakhstan satisfied with the quality of maternity care? Implementing the $\mathrm{WHO}$ tool to assess the quality of hospital services. Iran J Public Health. 2016;45(6):729-38.

\section{PMid:27648415}

9. Sierra D, Wood M, Kolli S, Felipez LM. Pediatric gastritis, gastropathy, and peptic ulcer disease. Pediatr Rev. 2018;39(11):542-9. http://doi.org/10.1542/pir.2017-0234 PMid:30385583

10. Sipponen $P$, Maaroos HI. Chronic gastritis. Scand J Gastroenterol. 2015;50(6):657-67. http://doi.org/10.3109/00365 521.2015 .1019918

PMid:25901896

11. Stinton LM, Shaffer EA. Epidemiology of gallbladder disease: Cholelithiasis and cancer. Gut Liver. 2012;6(2):172-87. http:// doi.org/10.5009/gnl.2012.6.2.172

PMid:22570746

12. Ciccone S, Guerrini G, Lacorte D, Govoni MR. PP40 Acute pancreatitis in children and adolescents. Dig Liver Dis. 2011;43:S426.

13. Raman M, Milestone AN, Walters JR, Har AL, Ghosh S. Vitamin D and gastrointestinal diseases: Inflammatory bowel disease and colorectal cancer. Ther Adv Gastroenterol. 2011;4(1):49-62. http://doi.org/10.1177/1756283X10377820

PMid:21317994

14. Haimi M. Nutritional deficiencies in the pediatric age group in a multicultural developed country, Israel. World J Clin Cases. 2014;2(5):120-5. http://doi.org/10.12998/wjcc.v2.i5.120 PMid:24868510

15. Abu-El-Haija M, Uc A, Werlin SL, Freeman AJ, Georgieva M, Jojkić-Pavkov $D$, et al. Nutritional considerations in pediatric pancreatitis: A position paper from the NASPHAN pancreas committee and ESPHAN cystic fibrosis/pancreas working group. J Pediatr Gastroenterol Nutr. 2018;67(1):131-43. http:// doi.org/10.1097/MPG.0000000000002023 PMid:29927872

16. Gromova O, Doschanova A, Lokshin V, Tuletova A, Grebennikova G, Daniyarova L, et al. Vitamin D deficiency in Kazakhstan: Cross-sectional study. J Steroid Biochem Mol Biol. 2020;199:105565. http://doi.org/10.1016/j.jsbmb.2019.105565 PMid:31812522

17. Yelissinova N, Grjibovski AM, Yelissinova A, Rakhypbekov T, Semenova Y, Smailova $Z$, et al. Sociodemographic factors associated with infant abandonment in maternity hospitals in Kazakhstan: A case-control study. Public Health. 2015;129(7):1010-3. http://doi.org/10.1016/j.puhe.2015.04.009 PMid:25986952 